\section{Stres peran dan kinerja karyawan: pengujian model hubungan inverted-U}

\author{
Hendryadi \\ Manajemen, Sekolah Tinggi Ilmu Ekonomi Indonesia Jakarta
}

\begin{abstract}
The purpose of this study is to examine the impact of role stress (role overload, role ambiguity, and role conflict) on the frontline employees' performance. The study employs a direct survey through a self-administered questionnaire handed out to 132 employees in the restaurant business in Jakarta, Indonesia. Hierarchical Regression Analysis is used to test the hypotheses. The finding of the study shows that the role conflict and role ambiguity affects negatively to the performance, while role overload has a positive effect. Locus of control is proven to moderate the relationship between role overload-performance and role-ambiguity-performance, but not for role conflict - performance. Implications for managers are important to reduce the role conflict and role ambiguity in the workplace to maximize employee performance.
\end{abstract}

\begin{abstract}
Abstrak
Tujuan dari penelitian ini adalah untuk menguji dampak dari stres peran (role overload, ambiguity peran, dan konflik peran) pada kinerja karyawan garis depan. Penelitian ini menggunakan survei langsung melalui kuesioner yang diberikan sendiri kepada 132 karyawan di bisnis restoran di Jakarta, Indonesia. Analisis Regresi Hirarki digunakan untuk menguji hipotesis. Temuan penelitian menunjukkan bahwa konflik peran dan ambiguitas peran berpengaruh negatif terhadap kinerja, sementara peran yang berlebihan memiliki efek positif. Lokus kendali terbukti memoderasi hubungan role overload dan ambiguitas peran, tetapi tidak dalam konflik peran - kinerja. Implikasinya bagi manajer adalah bahwa upaya perlu dilakukan untuk mengurangi konflik peran dan ambiguitas peran karena memiliki implikasi negatif pada kinerja karyawan. Sedangkan kelebihan peran yang dirasakan oleh karyawan dipertahankan pada tingkat yang moderat untuk mempertahankan kinerja karyawan.
\end{abstract}

*Email korespondensi: hendry.basrah@gmail.com

Pedoman Sitasi: Hendryadi (2019). Stres kerja dan kinerja karyawan: model hubungan inverted-U. Jurnal Manajemen Strategi dan Aplikasi Bisnis, 1(2), 127 - 136.
JMSAB

127

Paper type

Research paper

Keywords: role stressor role overload, role ambiguity, role conflict, performance

Received: 24 Jun 2019

Revised: 12 Jul 2019

Accepted: 16 Aug 2019

Online: 31 Aug 2019

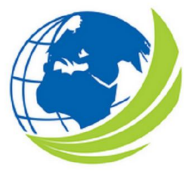

\author{
Jurnal Manajemen \\ Strategi dan Aplikasi \\ Bisnis, Vol 1, No. 2 , \\ Desember 2018, \\ pp. 127 - 136 \\ eISSN 2655-237X
}




\section{PENDAHULUAN}

Dalam kehidupan organisasi, stres kerja merupakan faktor yang sulit untuk dihindari. Stres kerja yang timbul akibat ketidakmampuan individu dalam menyelesaikan persoalan terkait kerja, baik dalam bentuk beban kerja yang terlalu tinggi, atau sumber-sumber tekanan lain yang dapat mempengaruhi sikap dan perilaku kerja karyawan. Griffin (2006) menyebutkan bahwa kehidupan bisnis memiliki banyak sumber stres. Jika didasarkan pada Conservation of Resources Theory (COR), karyawan dapat mengalami stres ketika mereka dihadapkan pada bahaya kehilangan sumber daya; mereka kehilangan sumber daya; atau mereka tidak dapat mencapai hasil yang diharapkan meskipun sumber dayanya tersedia untuk digunakan (Hobfoll, dikutip dari Akgunduz, 2015). Di sisi lain, terlepas dari berbagai masalah di tempat kerja, karyawan juga dapat terpapar stres kerja yang berasal dari kehidupan rumah tangga / keluarga (Chiang et al., 2010).

Stres kerja telah banyak dinyatakan memiliki efek merugikan bagi organisasi. Organisasi Perburuhan Internasional (ILO) melaporkan bahwa ketidakefisienan yang timbul dari tekanan pekerjaan mungkin berjumlah 10 persen dari produk nasional bruto (GNP) suatu negara (Mills et al. (2017). Mwangi (2015) menyebutkan bahwa stres terkait dengan pekerjaan mempengaruhi kinerja individu dan menghasilkan perilaku yang tidak diinginkan seperti merokok dan minum-minuman keras secara berlebihan, dan juga menyebabkan depresi dan kecemasan ketika individu tersebut tidak mampu untuk memenuhi tuntutan yang saling bertentangan dan tanggung jawab pekerjaan yang ada di perusahaan Institut Nasional untuk Keselamatan dan Kesehatan Kerja (2010) menegaskan bahwa dengan berlalunya waktu, kondisi kerja telah banyak berkembang dan tekanan kerja telah menjadi fokus untuk yang jauh lebih penting untuk diperhatikan oleh pihak manajemen perusahaan.

Salah satu isu yang paling banyak diperdebatkan oleh para peneliti terkait dengan stres kerja adalah bagaimana pengaruh stres kerja terhadap kinerja. Sumber daya manusia sebagai asset utama perusahaan telah menjadi pusat kajian para peneliti di bidang manajemen dan organisasi, terutama bagaimana perusahaan dapat mempertahankan dan atau meningkatkan kinerja karyawannya. Oleh karena itu, kinerja merupakan salah satu variabel paling relevan yang perlu diperiksa sebagai respon dari stres kerja. Quick dan Henderson (2016) menekankan bahwa stres dapat menyebabkan gangguan serius di tempat kerja, baik dari sisi individu maupun produktivitas organisasi secara keseluruhan. Stres dianggap menjadi penyebab masalah seperti komitmen yang rendah, ketidakpuasan kerja, alkoholisme, ketidakhadiran, penyakit fisik, dan penurunan kinerja (Robbins dan Judge, 2016; Paais, 2018; Aditya \& Kusuma, 2019). Meskipun banyak penelitian menyatakan bahwa stres dapat mengurangi kualitas dan kuantitas kerja, banyak pula penelitian yang memberikan kesimpulan yang berlawanan, yaitu stres justru dapat meningkatkan kinerja. Istilah ini dikenal dengan kurva terbalik (inverted-U).

Pengaruh positif stres kerja terhadap kinerja didukung oleh teori Teori Aktivasi atau Teori Gairah (Scott, 1966, dalam Bruggen, 2015). Teori ini sendiri berasal dari Hukum Yerkes Dodson (Yerkes dan Dodson, 1908) atau dikenal dengan singkatan YDL menjelaskan bagaimana aktivasi psikologis seseorang diperlukan agar karyawan termotivasi untuk berkinerja yang efektif dan efisien dan untuk mencapai tujuan organisasi. Meskipun YDL banyak dikritik oleh para teoretikus modern (Corbett, 2015), namun faktanya hubungan positif stres kerja dengan kinerja ini telah banyak didukung secara empiris (seperti Bruggen, 2015). Menindaklanjuti perbedaan yang sudah diuraikan di atas, maka penelitian ini bertujuan untuk menguji relevansi hubungan kurva terbalik antara stres kerja dan kinerja karyawan di sektor jasa restoran di Jakarta.

Penelitian ini berkontribusi pada literatur dalam beberapa cara. Pertama, klarifikasi pada model kurva terbalik pada hubungan stres dengan kinerja kemungkinan berbeda karena ada perbedaan sektor pekerjaan, dan faktor individual lainnya (seperti kemampuan menangani stres, locus of control). Sektor jasa restoran memiliki karakteristik berbeda dimana karyawan dihadapkan pada tekanan internal dari perusahaan (terkait dengan beban kerja), dan dari tuntutan eksternal 
(pelanggan). Karena kelebihan beban kerja dan tuntutan bersaing yang datang dari manajemen dan pelanggan, karyawan garis depan sering kali merasa tertekan (Zhao, 2016). Oleh karenanya, riset ini memperluas cakupan studi stres kerja pada karyawan yang khusus bekerja di sektor jasa restoran. Kedua, penelitian sebelumnya lebih banyak menggunakan respon stres (seperti kesulitan tidur, merasa lelah berlebihan dan lainnya) sebagai pengkur tingkat stres. Penelitian ini mengadaptasi model penelitian yang dilakukan oleh Akgunduz (2015) dan menempatkan 3 variabel penyebab stres meliputi: role ambiguity, role conlict dan role overload sebagai indikator stres. Berbeda dengan studi yang dilakukan oleh Akgunduz (2014) yang menempatkan self-efficacy sebagai variabel tambahan, penelitian ini menempatkan locus of control sebagai pemoderasi hubungan stres kerja dan kinerja. Hasil penelitian ini juga memiliki implikasi manajerial secara langsung kepada manajer untuk mengelola stres kerja karyawan.

\section{KAJIAN PUSTAKA}

Stres kerja

Stres kerja oleh Luthans (2002) dinyatakan sebagai kondisi ketegangan yang dapat mempengaruhi emosi, proses berpikir dan kondisi seorang pekerja. Kondisi yang cenderung menjadi penyebab stres disebut sebagai stressor. Lebih lanjut, tiga komponen stresor dikelompokkan menjadi stressor dari luar organisasi, stressor level organisasi, stresor kelompok, dan stresor di tingkat individu. Dalam penelitian ini, stres didekati dari sisi pekerjaan / tugas atau disebut dengan role stress. Ini dapat muncul sebagai hasil dari pemutusan antara bagaimana karyawan memandang peran mereka dan keberhasilan yang mereka raih (Lambert dan Lambert, dalam Akgunduz, 2015). Dengan kata lain, stres model ini dapat terjadi ketika ada perbedaan antara harapan dan pencapaian peran yang dirasakan. Karena adanya perbedaan kemampuan untuk menahan stres, maka kekuatan untuk mengatasi stres dan respons stres antar individu dapat berbeda-beda. Perbedaan-perbedaan ini dapat disebabkan oleh fitur pribadi karyawan, pekerjaan itu sendiri atau fitur tidak langsung yang terkait dengan organisasi (Jung dan Yoon, 2013).

Konflik peran, peran berlebihan, dan ambiguitas peran adalah tiga komponen utama dari stres peran (Cooper dan Marshall, 1976; Akgunduz, 2015). Ambiguitas peran terjadi ketika ada ambiguitas dalam peran seseorang dalam organisasi atau ketika orang itu tidak tahu apa yang harus dilakukan atau bagaimana melakukan perannya. Konflik peran terjadi ketika karyawan dihadapkan dengan harapan peran yang berbeda, seperti ketika dua peran harus dilakukan secara bersamaan atau ketika melakukan satu peran mencegah melakukan yang lainnya. Kelebihan peran meningkat ketika pemenuhan peran menjadi tidak mungkin bagi individu karena waktu, energi atau sumber daya yang terbatas.

\section{Stres peran dan kinerja}

Quick dan Henderson (2016) menekankan bahwa stres dapat menyebabkan gangguan serius di tempat kerja, baik dari sisi individu maupun produktivitas organisasi secara keseluruhan. Stres dianggap menjadi penyebab masalah seperti komitmen yang rendah, ketidakpuasan kerja, alkoholisme, ketidakhadiran, penyakit fisik, dan penurunan kinerja (Robbins dan Judge, 2016; Paais, 2018; Aditya \& Kusuma, 2019). Paais (2018) dalam penelitiannya menemukan efek negative stres pada kinerja karyawan di sektor perbankan.

Kelebihan peran adalah bentuk konflik peran-orang, persepsi bahwa tuntutan peran sangat besar dibandingkan kemampuan dan sumber daya yang tersedia. Dalam lingkungan tugas yang kompleks, role overload sering dimanifestasikan sebagai bentuk konflik di mana individu diharapkan untuk memenuhi harapan pengirim peran ganda (Jones et al., 2007). Tenaga frontliner memiliki banyak efek negatif dari peran yang berlebihan. Role overload juga ditemukan memiliki efek negative (Jones et al., 2007) dan positif (Akgunduz, 2015) terhadap kinerja. Penelitian terbaru yang dilakukan oleh Prihantari dan dan Astika (2019) menemukan bahwa role overload memiliki pengaruh negative terhadap kinerja karyawan. Berdasarkan argument tersebut, hipotesis yang diajukan adalah: 


\section{$\mathrm{H}_{1}$ : role overload berpengaruh signifikan terhadap kinerja}

Selain kelebihan beban kerja, dimensi lain dari stressor pekerjaan adalah ambiguitas peran. Dalam teori klasik, ambiguitas peran didefinisikan sebagai kurangnya informasi yang diperlukan tersedia untuk fungsi tertentu dalam organisasi. Lebih khusus lagi, ambiguitas peran menunjukkan kurangnya kejelasan tentang peran karyawan, tanggung jawab dan / atau prosedur untuk mencapai apa yang diharapkan dari mereka (dalam Zhou et al., 2016). Ambiguitas peran telah dinyatakan memberikan efek negative terhadap kinerja (Akgunduz, 2015; Amilin, 2017), dan oleh karenanya hipotesis yang diajukan adalah:

$\mathrm{H}_{2}$ : role ambiguity berpengaruh signifikan terhadap kinerja

Konflik peran terjadi ketika karyawan dihadapkan dengan harapan peran yang berbeda, seperti ketika dua peran harus dilakukan secara bersamaan atau ketika melakukan satu peran mencegah melakukan yang lainnya. Hubungan antara konflik peran dalam penelitian sebelumnya telah ditemukan berbeda, misalnya konflik peran berpengaruh negatif terhadap kinerja akuntan (Amilin, 2017; Shaukat, Yousaf, \& Sanders, 2017). Namun Fahmi et al. (2019) menemukan efek sebaliknya, yaitu konflik peran memiliki pengaruh positif dan signifikan terhadap kinerja karyawan (Fahmi et al., 2019). Berdasarkan landasan empiris tersebut, hipotesis yang diajukan adalah:

$\mathrm{H}_{3}$ : role conflict berpengaruh signifikan terhadap kinerja

Peran locus of control sebagai moderator

Locus of control adalah evaluasi individu terhadap lingkungan mereka dan seberapa responsifnya lingkungan terhadap tindakan mereka (Johnson et al., 2015; Rotter, 1966). Individu dengan lokus kontrol internal yang lebih besar (atau disebut disebut sebagai lokus kendali internal) cenderung percaya bahwa lingkungan responsif terhadap tindakan mereka dan bahwa interaksi dengan lingkungan akan menghasilkan hasil yang dapat diprediksi. Sebaliknya, individu dengan lokus kontrol eksternal yang lebih besar (lokus kendali eksternal') cenderung menafsirkan lingkungan dan hasil merupakan interaksi dengan lingkungan di luar kendali mereka. Dengan kata lain, individu yang memiliki keyakinan bahwa lingkunganlah yang mempunyai kontrol terhadap nasib atau event-event yang terjadi dalam kehidupannya dikatakan individu tersebut memiliki external locus of control (Hendryadi, 2017; Suprayogi, 2017). Menurut Chen dan Silverthorne (2008), locus of control internal yang lebih tinggi berkontribusi pada tingkat stres kerja yang lebih rendah, karena internal bekerja secara efektif dengan peristiwa-peristiwa stres yang bertentangan dengan eksternal, yang percaya bahwa nasib atau keberuntungan mengendalikan hasil hidup mereka (Gray-Stanley et al., 2010). Stres yang diterima adalah tingkat stres dari suatu peristiwa tertentu, dengan pengaruh lingkungan individu, sifat-sifat kepribadian, dan kemampuan untuk mengatasi stresor (Cohen, Kamarck, \& Mermelstein, 1983; dalam Li, Lepp, \& Barkley, 2015). Studi ini mengusulkan bahwa hubungan antara stres peran dengan kinerja dimoderasi oleh locus of control.

$\mathrm{H}_{4}(\mathrm{a}, \mathrm{b}, \mathrm{c})$ : locus of control memoderasi hubungan role stress (role opverload, role ambiguity, and role conflict) dengan kinerja karyawan

\section{METODE}

Penelitian ini menggunakan pendekatan kuantitatif untuk menjelaskan hubungan antara hubungan role stress (role opverload, role ambiguity, and role conflict) dengan kinerja karyawan. Pendekatan survey dengan metode cross-sectional (yaitu data diambil dalam satu waktu) dengan menyebarkan kuesioner kepada responden dilakukan untuk memperoleh data primer.

\section{Prosedur Sampel}

Sampel penelitian adalah karyawan yang bekerja di bisnis restoran di Jakarta. Menggunakan pendekatan convience sampling, tiga lokasi survey ditentukan. Sebanyak 132 orang responden 
berpartisipasi sebagai responden. Rentang usia responden berkisar antara 19 - 29 dengan standar deviasi 1.63. Mayoritas responden (82\%) adalah wanita, dan 91\% berpendidikan SMU/ sederajat.

Pengukuran

Intrumen pengukuran diadaptasi dari berbagai penelitian sebelumnya. Role stress (role opverload, role ambiguity, dan role conflict) diadaptasi dari Skala multi-item dari Beehr dan Newman (1978), Cooper dan Marshall (1976), Rizzo et al. (1970); Tang dan Chang (2010) yang diuji ulang oleh Akgunduz (2015) untuk mengukur persepsi karyawan tentang stres peran. Delapan belas item digunakan untuk mengukur tiga dimensi stres peran. Estimasi nilai alpha Cronbach untuk mengukur tingkat konsistensi internal pada setiap konstruk berkisar pada angka yang dapat diterima yaitu dari 0,783 dan 0,825 (ambiguitas peran=0,783; konflik peran=0,814; dan kelebihan peran $=0,825$ ). Beberapa contoh item yang digunakan antara lain: (1) Saya bekerja dengan dua atau lebih kelompok yang memiliki peran berbeda (role conflict); (2) saya memiliki tujuan dan sasaran yang jelas dan terencana dalam pekerjaan saya (role ambiguity); dan (3) saya merasa yakin tentang seberapa besar kewenangan yang saya miliki (role overload). Skala pengukuran mengggunakan Likert Type Item meliputi skor 1 (sangat tidak setuju) s/ d 7 (sangat setuju).

Locus of control diadaptasi dari 8-item locus of control yang dikembangkan oleh Hendryadi (2017). Contoh pertanyaan adalah: (1)Keberhasilan saya sepenuhnya ada di tangan saya (Internal); dan (2) karir saya sekarang sepenuhnya di tangan atasan (eksternal). Nilai koefisien Cronbach Alpha adalah sebesar 0.724 dan sudah memenuhi syarat keandalan konsistensi internal.

Kinerja diukur berdasarkan penilaian atasan langsung dengan mengadopsi model penilaian untuk mengukur kinerja layanan yang dirasakan (Cho et al., 2016). Contoh item adalah "tersedia ketika pelanggan membutuhkan layanan". Nilai koefisien Cronbach Alpha sebesar 0.788 menunjukkan bahwa instrumen sudah memiliki keandalan yang baik.

Teknik analisis

Pertama, uji independent t-test dilakukan untuk menguji apakah ada perbedaan yang signifikan dalam jenis kelamin pada tingkat stres dan kinerja. Setelah itu, dua analisis regresi hirarkis dilakukan untuk menyelidiki efek moderasi dari perbedaan locus of control pada hubungan role stress dengan kinerja. Karena regresi hirarkis adalah teknik statistik yang sering digunakan dan secara luas dianggap sesuai untuk memperkirakan efek moderasi, maka teknik ini dianggap pendekatan yang tepat untuk model penelitian yang diajukan (Phillips \& Jang, 2007; Lu \& Gursoy, 2016). Summated scale atau total skor dari masing-masing sub-konstruksi role stress (role opverload, role ambiguity, dan role conflict) dan kinerja dihitung dengan menjumlahkan semua item pada masing-masing subkonstrak dan kemudian rata-rata untuk membentuk skor komposit individu untuk analisis. Dua variabel dummy yang menunjukkan perbandingan dua kelompok dibuat untuk menguji efek moderasi locus of control ( 1 =internal locus of control dan $2=$ eksternal locus of control). Untuk setiap analisis regresi hirarkis, gender dan usia dimasukkan dalam model sebagai variabel kontrol terlebih dahulu; setiap subdimensi role stress dan dua variabel dummy dimasukkan ke dalam persamaan kedua; dan interaksi locus of control dengan role stress ditambahkan dalam persamaan. Persamaan yang diuji adalah sebagai berikut:

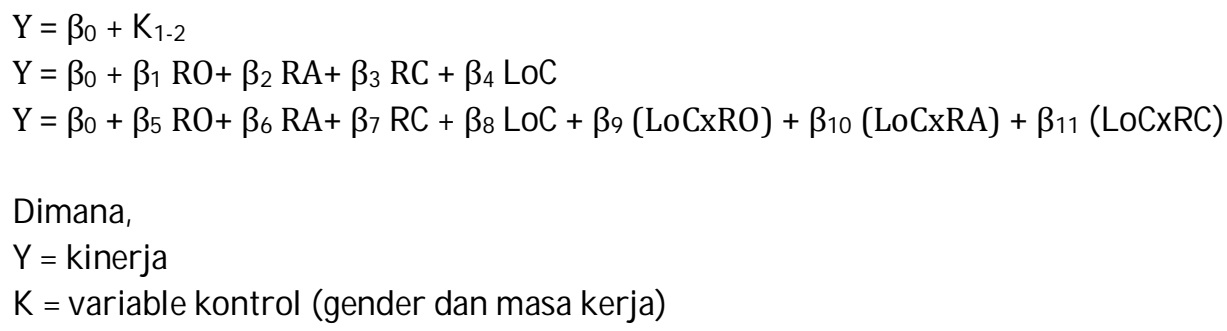


$\mathrm{RO}=$ role overload

$\mathrm{RA}=$ role ambiguity

$\mathrm{RC}=$ role conflict

LoC $=$ Locus of Control

\section{HASIL DAN PEMBAHASAN}

\section{Analisis deksriptif}

Tabel 1 menyajikan cara, standar deviasi, dan korelasi antara tiga dimensi role stress, locus of control dan kinerja. Temuan menunjukkan bahwa role ambiguity (RA) dan role conflict (RC) keduanya memiliki hubungan negatif yang signifikan dengan kinerja( $r=-.268, p<01 ; r=-.248, p<01)$. Seluruh variabel role stress memiliki hubungan positif dengan locus of control $(R A=0.308, p<0.2$; $\mathrm{RC}=0.220, \mathrm{p}<0.05 ; \mathrm{RC}=0.397, \mathrm{p}<0.01)$. Hubungan antara locus of control dan kinerja adalah negative namun tidak signifikan $(r=-.054, \mathrm{p}>0.05)$.

Tabel 1. Mean, Standar deviasi dan Korelasi antar variabel

\begin{tabular}{lcccccc}
\hline & SD & RO & RA & RC & LOC & PERF \\
\hline RO & 1.762 & $(0.825)$ & & & & \\
RA & 1.877 & .084 & $(0.783)$ & & & \\
RC & 1.845 & .112 & $.368^{* *}$ & $(0.814)$ & & \\
LoC & 2.120 & $.308^{* *}$ & $.220^{*}$ & $.397^{* *}$ & $(0.724)$ & \\
PERF & 2.828 & .144 & $-.268^{* *}$ & $-.248^{* *}$ & -.054 & $(0.788)$ \\
\hline
\end{tabular}

Sumber: data lapangan, diolah (2018); ${ }^{* *}$ Correlation is significant at the 0.01 level (2-tailed).

*Correlation is significant at the 0.05 level (2-tailed).

Regresi dan pengujian hipotesis

Tabel 2 menyajikan hasil analisis regresi untuk efek moderasi locus of control pada hubungan role stress - kinerja. Role ambiguity dan role conflict ditemukan berhubungan negative dengan kinerja (H1 dan $\mathrm{H} 2$ terdukung), sedangkan role overload berhubungan positif dan signifikan (H3 terdukung). Locus of control menunjukkan hubungan positif namun tidak signifikan dengan kinerja setelah dikendalikan oleh gender dan masa kerja.

Locus of control memiliki peran moderasi pada hubungan role overload dan role ambiguity, namun tidak untuk hubungan role conflict - kinerja. Berdasarkan temuan ini dapat dinyatakan bahwa locus of control hanya memiliki efek moderasi pada hubungan RO dan Kinerja dan RA dan kinerja.

Penambahan variabel locus of control pada Model 2 dapat meningkatkan nilai adjusted RSquare pada model $2(\Delta \mathrm{R} 2=.100, \mathrm{p}<.05)$, dan penambahan variabel interaksi locus of control dengan tiga variabel role stress menambahkan variasi inkremental yang signifikan $(\Delta \mathrm{R} 2=.229$, $\mathrm{p}<$ .05). Dengan demikian dapat dinyatakan bahwa hipotesis $4 a$ dan $4_{b}$ didukung, tetapi hipotesis $4_{c}$ tidak didukung.

Pembahasan

Tujuan dari penelitian ini adalah untuk menjelaskan pengaruh stres peran terhadap kinerja pekerjaan karyawan restoran dengan menempatkan locus of control sebagai moderator. Berdasarkan hasil analisis diketahui bahwa konflik peran dan ambiguitas peran mempengaruhi kinerja karyawan secara negatif, sedangkan role overload memiliki pengaruh positif terhadap kinerja.

Role overload ditemukan memiliki dampak peningkatan kinerja pada karyawan dan mendukung temuan (Akgunduz, 2015) dan bertentangan dengan temuan Jones et al. (2007) dan Prihantari dan dan Astika (2019) menemukan bahwa role overload memiliki pengaruh negative terhadap kinerja karyawan. Dapat dinyatakan bahwa model kurva terbalik (inverted-U) terdukung 
dalam model hubungan role overload-kinerja. Hal ini berarti peran kelebihan oleh karyawan yang bekerja di sektor restoran bukan menjadi penghambat mereka untuk bekerja secara baik. Beban kerja yang tinggi terutama di hari libur (dan karyawan dilarang untuk mengambil hari libur di saat week-end) sudah ditanggapi secara biasa oleh responden. Selain itu, tingkat pendidikan mayoritas responden adalah SMU sederajat menjadikan alasan mengapa mereka tetap bertahan di pekerjaan sekarang dan tetap menampilkan kinerja baik. Sempitnya kesempatan untuk mencari pekerjaan lain kemungkinan menjadikan salah satu penyebab mengapa ketika karyawan dibebani pekerjaan yang tinggi tetap menampilkan kinerja baik.

Role ambiguity dan role conflict ditemukan berhubungan negative dengan kinerja. Hasil ini tidak mendukung model kurva terbalik (inverted-U) pada hubungan stres-kinerja. Penelitian ini mendukung temuan Akgunduz (2015) dan Amilin (2017) mengenai efek negative ambiguitas peran terhadap kinerja, serta mendukung temuan Amilin (2017); Shaukat, Yousaf, \& Sanders, (2017) mengenai efek negative role conflict terhadap kinerja.

Tabel 2. Hasil R egresi

\begin{tabular}{|c|c|c|c|c|c|c|}
\hline & \multicolumn{2}{|c|}{ Model 1} & \multicolumn{2}{|c|}{ Model 2} & \multicolumn{2}{|c|}{ Model 3} \\
\hline & B & Sig. & B & Sig. & B & Sig. \\
\hline Gender & -.355 & .478 & -.172 & .720 & -.182 & .684 \\
\hline Tenure & .240 & .465 & .373 & .247 & -.040 & .907 \\
\hline $\mathrm{RO}$ & & & .266 & .022 & .271 & .029 \\
\hline RA & & & -.322 & .018 & -.374 & .004 \\
\hline $\mathrm{RC}$ & & & -.329 & .031 & -.485 & .001 \\
\hline LoC & & & .029 & .817 & .066 & .592 \\
\hline M1 (RO x LoC) & & & & & -2.601 & .000 \\
\hline M2 (RA x LoC) & & & & & -1.209 & .040 \\
\hline M3 (RCx LoC) & & & & & .293 & .281 \\
\hline$\Delta \mathrm{R}_{2}$ & & -.008 & & .100 & & .229 \\
\hline F & & .497 & & 3.428 & & 5.329 \\
\hline
\end{tabular}

Sumber: data lapangan, diolah (2018)

Berdasarkan sampel yang diambil dari sektor jasa restoran, penelitian ini tidak berhasil menemukan pengaruh signifikan locus of control pada kinerja. Meskipun secara spesifik tidak diajukan dalam hipotesis, hubungan antara locus of control dengan stres peran seluruhnya positif dan signifikan. Hasil ini sejalan dengan tidak sejalan dengan temuan Chen dan Silverthorne (2008) yang menjelaskan bahwa locus of control internal yang lebih tinggi berkontribusi pada tingkat stres kerja yang lebih rendah. Temuan ini justru mendukung Karkoulian et al. (2016) yang menemukan hubungan positif antara locus of control internal dan stres yang dirasakan. Terlepas dari jenis kelamin dan masa kerja, locus of control terbukti memiki peran moderasi pada hubungan role overload - kinerja dan role ambiguity - kinerja. Karena itu, dapat dinyatakan bahwa ketika karyawan mengalami ambiguitas peran dan peran yang berlebihan, dibandingkan dengan konflik peran, mereka terpapar pada tingkat stres peran yang lebih tinggi, akibatnya kinerja mereka semakin menurun. Berdasarkan hasil ini maka dimungkinkan untuk menyatakan fokus untuk mengurangi ambiguitas peran dan konflik peran dapat diprioritaskan karena memiliki efek negative pada kinerja.

\section{KESIMPULAN}

Industri jasa restoran merupakan salah satu industry yang berkembang pesat di Jakarta, dan terus mengalami pertumbuhan dari tahun ke tahun. Kondisi ini menjadikan industry ini salah satu industry yang memiliki tingkat persaingan yang ketat. Dalam kondisi seperti itu, perusahaan dituntut 
untuk mengelola sumber daya mereka secara maksimal untuk mencapai kinerja perusahaan secara keseluruhan. Penelitian ini berfokus pada pembuktian teori inverted-U pada hubungan stres-kinerja yang masih menjadi perdebatan sampai saat ini. Stres peran dianalisis melalui tiga dimensi meliputi ambiguitas peran, konflik peran, dan kelebihan peran. Hasil analisis memperlihatkan ketiga dimensi tersebut memiliki arah yang berbeda, dimana kelebihan peran (role overload) memiliki efek positif pada kinerja, sedangkan dua dimensi lain yaitu konflik peran dan ambiguitas peran mempengaruhi kinerja karyawan secara negatif. Dengan demikian dapat dinyatakan bahwa model kurva terbalik (inverted-U) terdukung dalam model hubungan role overload-kinerja. Peran moderasi locus of control pada hubungan stres peran - kinerja terdukung pada hubungan role overload dan role ambiguity, namun tidak untuk hubungan role conflict - kinerja.

Implikasi

Berdasarkan kesimpulan yang diperoleh, implikasi bagi para manager adalah perlu dilakukan upaya untuk mengurangi konflik peran dan ambiguitas peran karena memiliki implikasi negative pada kinerja karyawan. Sedangkan kelebihan peran yang dirasakan oleh karyawan tetap dijaga pada level moderat untuk tetap menjaga kinerja karyawan. Pihak manajemen perlu meminimalkan faktorfaktor yang dapat mengarah kepada ambiguitas dan konflik peran dengan memberikan deskripsi pekerjaan yang jelas mengenai tanggung jawab pekerjaan. Selain itu, untuk menjaga beban kerja di level moderat, perlu dilakukan analisis beban kerja dengan tetap mempertimbangkan waktu, tenaga, dan kemampuan karyawan.

\section{Keterbatasan}

Penelitian ini memiliki keterbatasan dari sisi sampel dan variabel penelitian yang digunakan. Dari sisi sampel, penggunaan sampel sebesar 132 dengan metode convenience memiliki kelamahan generalisasi hasil. Penelitian berikutnya perlu memperluas wilayah penelitian dan penambah ukuran sampel untuk memperbesar peluang generalisasi hasil pada isu stres kerja dan kinerja. Selain itu, penelitian ini tidak mempertimbangkan faktor kepribadian lain seperti self-efficacy sebagai predictor kinerja, dan work-family conlict sebagai predictor stres kerja terutama pada wanita. Riset mendatang perlu mempertimbangkan level stres berdasarkan gender, menambahkan variabel self-efficacy dan work-family conlict ke dalam model penelitian.

\section{REFERENSI}

Aditya, A. G. D., \& Kusuma, M. G. W. (2019). The effect of tri hita karana culture in relationship between work stress and internal auditor performance. International research journal of management, IT and social sciences, 6(2), 72-78.

Ahmad, E. H., Maidin, A., Abdullah, T., Naiem, F., Buraerah, S., Handayanif, R., \& Prihantono, P. (2018). Relationship of Work Stress to the Performance of Intensive Care Unit Nurses in Makassar. American Journal of Public Health, 6(1), 18-20.

Akgunduz, Y. (2015). The influence of self-esteem and role stress on job performance in hotel businesses. International Journal of Contemporary Hospitality Management, 27(6), 1082-1099.

Amilin, A. (2017). The Impact of Role Conflict and Role Ambiguity on Accountants' Performance: The Moderating Effect of Emotional Quotient. European Research Studies, 20(2), 237.

Bruggen, A. (2015). An empirical investigation of the relationship between workload and performance. Management Decision, 53(10), 2377-2389.

Corbett, M. (2015). From law to folklore: work stress and the Yerkes-Dodson Law. Journal of Managerial Psychology, 30(6), 741-752.

Chaby, L. E., Sheriff, M. J., Hirrlinger, A. M., \& Braithwaite, V. A. (2015). Can we understand how developmental stress enhances performance under future threat with the Yerkes-Dodson law?. Communicative \& integrative biology, 8(3), e1029689. 
Chen, J. C., \& Silverthorne, C. (2008). The impact of locus of control on job stress, job performance and job satisfaction in Taiwan. Leadership \& Organization Development Journal, 29(7), 572-582.

Chiang, F. F., Birtch, T. A., \& Kwan, H. K. (2010). The moderating roles of job control and work-life balance practices on employee stress in the hotel and catering industry. International Journal of Hospitality Management, 29(1), 25-32.

Cho, M., Bonn, M. A., Han, S. J., \& Lee, K. H. (2016). Workplace incivility and its effect upon restaurant frontline service employee emotions and service performance. International Journal of Contemporary Hospitality Management, 28(12), 2888-2912.

Fahmi, H. K., Musnadi, S., \& Nadirsyah, N. (2019). Role Conflict, Self Efficacy, Employees' Performance and Organizational Performance. Journal of Accounting Research, Organization and Economics, 2(1), 31-40.

Gray-Stanley, J. A., Muramatsu, N., Heller, T. S., Hughes, S., Johnson, T. P., \& Ramirez-Valles,J. (2010).Work stress and depression among direct support professionals: The role ofwork support and locus of control.Journal of Intellectual Disability Research,54(8),749-761

Grifin, M.L. (2006), Gender and stress: a comparative assessment of sources of stress among correctional oficers, Journal of Contemporary Criminal Justice, Vol. 22 No. 1, pp. 4-25.

Hendryadi, H. (2017). PENGEMBANGAN SKALA LOCUS OF CONTROL. Jurnal Riset Manajemen dan Bisnis (JRMB) Fakultas Ekonomi UNIAT, 2(3), 417-424.

Jha, S., Balaji, M. S., Yavas, U., \& Babakus, E. (2017). Effects of frontline employee role overload on customer responses and sales performance: Moderator and mediators. European Journal of Marketing, 51(2), 282-303.

Luthans, F. (2002). The need for and meaning of positive organizational behavior. Journal of Organizational Behavior: The International Journal of Industrial, Occupational and Organizational Psychology and Behavior, 23(6), 695-706.

Jones, E., Chonko, L., Rangarajan, D., \& Roberts, J. (2007). The role of overload on job attitudes, turnover intentions, and salesperson performance. Journal of Business Research, 60(7), 663671.

Johnson, R. E., Rosen, C. C., Chang, C. H. D., \& Lin, S. H. J. (2015). Getting to the core of locus of control: Is it an evaluation of the self or the environment?. Journal of Applied Psychology, 100(5), 1568.

Jung, H. S., \& Yoon, H. H. (2013). Is the individual or the organization the cause of hotel employees' stress? A longitudinal study on differences in role stress between subjects. International Journal of Hospitality Management, 33, 494-499.

Karatepe, O. M., Yavas, U., Babakus, E., \& Deitz, G. D. (2018). The effects of organizational and personal resources on stress, engagement, and job outcomes. International Journal of Hospitality Management, 74, 147-161.

Karkoulian, S., Srour, J., \& Sinan, T. (2016). A gender perspective on work-life balance, perceived stress, and locus of control. Journal of Business Research, 69(11), 4918-4923.

Li, J., Lepp, A., \& Barkley, J. E. (2015). Locus of control and cell phone use: Implications for sleep quality, academic performance, and subjective well-being. Computers in Human Behavior, 52, 450-457.

Lu, A. C. C., \& Gursoy, D. (2016). Impact of job burnout on satisfaction and turnover intention: do generational differences matter?. Journal of Hospitality \& Tourism Research, 40(2), 210-235.

Mwangi, S. M. (2015). The Effect of Work Related Stressors on Employee Performance in Non-

Governmental Organizations In Kenya (Doctoral dissertation, United States International University-Africa).

Quick, J., \& Henderson, D. (2016). Occupational stress: Preventing suffering, enhancing wellbeing. International journal of environmental research and public health, 13(5), 459.

Paais, M. (2018). Effect of Work Stress, Organization Culture and Job Satisfaction toward Employee Performance in Bank Maluku. Academy of Strategic Management Journal.

Phillips, W., \& Jang, S. (2007). Destination image and visit intention: Examining the moderating role of motivation. Tourism Analysis, 12, 319-326.

Prihantari, G. A. P. E. D., \& Astika, I. B. P. (2019). Effect of role overload, budget participation, environmental uncertainty, organizational culture, competence, and compensation on 
employee performance. International research journal of management, IT and social sciences, 6(4), 197-206.

Robbins, S. P., \& Judge, T. (2015). A. 2015. Perilaku Organisasi, eds, 16. Jakarta: Salemba Empat

Shaukat, R., Yousaf, A., \& Sanders, K. (2017). Examining the linkages between relationship conflict, performance and turnover intentions: Role of job burnout as a mediator. International Journal of Conflict Management, 28(1), 4-23.

Smith, T. D., Hughes, K., DeJoy, D. M., \& Dyal, M. A. (2018). Assessment of relationships between work stress, work-family conflict, burnout and firefighter safety behavior outcomes. Safety science, 103, 287-292.

Suprayogi, T. T. (2017). LOCUS OF CONTROL DAN KINERJA KARYAWAN: UJI KOMPARASI. Jurnal Riset Manajemen dan Bisnis (JRMB) Fakultas Ekonomi UNIAT, 2(2), 131-138.

Tang, Y. T., \& Chang, C. H. (2010). Impact of role ambiguity and role conflict on employee creativity. African Journal of Business Management, 4(6), 869-881

Zhao, X. (2016). Work-family studies in the tourism and hospitality contexts. International Journal of Contemporary Hospitality Management, 28(11), 2422-2445.

Zhou, Q., Martinez, L. F., Ferreira, A. I., \& Rodrigues, P. (2016). Supervisor support, role ambiguity and productivity associated with presenteeism: A longitudinal study. Journal of Business Research, 69(9), 3380-3387.

\section{PROFIL PENULIS}

Hendryadi adalah dosen Prodi Manajemen Sekolah Tinggi Ilmu Ekonomi Indonesia Jakarta, dan Direktur Riset dan Konsultasi pada Lembaga Pengembangan Manajemen dan Publikasi (LPMP) Imperium. Bidang Kajian utama adalah perilaku organisasi, pengembangan skala, dan perbankan syariah. Penulis dapat dihubungi di email: hendry.basrah@gmail.com 